\title{
SIEMENTUOTANTOMME KEHITYKSESTÄ TUONNIN JA VIENNIN VALOSSA.
}

\author{
LiIsa Mali.
}

Saapunut 20. 7. 1948.

Maamme nykyinen siementuotanto on varsin heikko. Useimpien kasvilajien siemeniin nähden olemme täydellisesti tai suureksi osaksi ulkomaista riippuvaisia. Onpa viimeksi kuluneina vuosina tuotu maahan sellaistakin siementavaraa, jonka olimme ennen sotia pystyneet tuottamaan omassa maassamme.

Suomi on siis selvä siementen tuontimaa. Tilanne ei ole kuitenkaan aina ollut tällainen. Vielä viime vuosisadan alkupuolella ja puolivälissä maamme lienee ollut kylvösiemenen suhteen suurin piirtein omavarainen. Otettiinpa eräistä viljakasveısta (ruis, ohra, kaura) ja luonnonvaraisena kasvavasta nurmipuntarpäästä siementä niin runsaasti yli oman tarpeen, että pystyttiin harjoittamaan maastavientiäkin. Siemenviljaa vietiin mm. Ruotsiin, Norjaan, Tanskaan, Englantiin ja Itämerenmaihin. Suomalainen siemen olikin hyvin haluttua. Vuosisadan loppupuolella tapahtui kuitenkin käänne; siementavaramme kysyntä väheni sen huonontuneen laadun vuoksi. Tämän lisäksi useimmat ostajamaamme olivat alkaneet kehittää ripeästi omaa kasvinjalostustaan ja siementuotantoaan. Sitä mukaa kuin niiden siemenviljely edistyi, vaatimukset myös ulkomaiseen tavaraan nähden kasvoivat.

Kun ulkomailta kuului valituksia siementavaramme laadusta, alettiin täälläkin kiinnittää huomiota asiaan. Siementuotantomme heikkous tuli yhä selvemmin ilmi vuosisadan loppupuolella peltoviljelymme edistyessä. Siemenviljelymme ei ollut pystynyt seuraamaan peltoviljelymme kehitystä, ei laatunsa eikä paljoutensa puolesta, minkä vuoksi ulkomailta hankittavan siemenen tarve kasvoi. Ulkomailta saatu tavara oli kuitenkin monta kertaa laadultaan heikompaa kuin omassa maassamme tuotettu. Sitä paitsi eteläisemmistä maista peräisin oleva siemen ei alkuperänsä vuoksi useastikaan ollut kotimaisen veroista. Tämä koski erıtyisesti talvehtivia kasveja ja näistä ennen kaikkea nurmikasvejamme.

1900-luvun alkupuolella pyrittiin parantamaan siementuotantoamme. Perustettiinpa erityinen yhdistyskin, Suomen Kylvösiemenyhdistys (1904) asiaa ajamaan. Sen toiminnan aikana ilmeni varsin virkeätä siemenviljelyharrastusta. 1910-luvulla oli erittäinkin juurikasvien siemenviljelytoiminta vilkasta $(1,2,3)$. 
Siementavaran tuonti kasvoi kuitenkin samanaikaisesti. Ensimmäisen maailmansodan vuosina tuonti oli monien siementen kohdalta sangen huomattavaa. Viljakasvien siementen vienti oli loppunut; puntarpään- ja timoteinsiementä vietiin sen sijaan jatkuvasti, vaikkakin määrät olivat vähäiset.

Maailmansodan jälkeiset vuodet tyrehdyttivät syntyneen siemenviljelyharrastuksen. Kahdennenkymmenennen vuosisadan alkupuolella oli mm. läheisten naapurimaittemme Tanskan ja Ruotsin siementuotanto kehittynyt tuntuvasti. Varsinkin Tanskassa ja myös muissa varsinaisissa siementuotantomaissa siemenviljely oli sodan aiheuttaman suuren kysynnän johdosta laajentunut. Sodan päätyttyä menekkisuhteet häiriintyivät, ja syntyneen ylituotannon vuoksi hinnat laskivat. Halpa ulkomainen siemen vaikutti ratkaisevasti meidänkin siementuotantoomme, joka ei pystynyt suurempien tuotantokustannustensa vuoksi tasaväkiseen kilpailuun edullisemmassa asemassa olevien maitten kanssa. Halvempi ulkomainen siemen pääsi hallitsemaan siemenmarkkinoitamme.

Kahden maailmansodan välistä siementuotantomme kehitystä kuvastaa tavallaan sinä aikana tapahtunut siementavarain maahantuonti. Taulukossa 1 $(9,10,12,13)$ on tullin tilastojen mukaan lasketut keskimääräiset tuontiluvut kymmenvuotisjaksoilta 1920 - 29 ja 1930 -39. Jos verrataan 1930-luvun keskimääräisiä tuontilukuja 1920-luvun tuontimääriin, havaitaan, että kg-määrät ovat kasvaneet kaikkien muiden siemenlajien paitsi puna-apilan, tärkeimmän nurmipalkokasvimme, kohdalla. Puna-apilan suhteen tapahtuneeseen kehitykseen oli vaikuttanut osaltaan 1922 annettu määräys, jonka mukaan maahan sai tuoda vain virolaista ja ruotsalaista alkuperää olevaa puna-apilansiementä. Sama määräys koski myös alsikeapilansiementä, jonka tuonti myös Latviasta tuli luvalliseksi vuodesta 1924.

Jo 1920-luvulla oli vuosia, jolloin puna-apilansiemenen tuonti oli vähäistä. Tällä kymmenluvulla sattui kuitenkin useita huonoja siemenvuosia (1923, 1928, 1929), joiden johdosta oli pakko tuoda maahan puna-apilansiementä melko runsaasti. 1930-luvun alusta puna-apilan siementuotantomme kehittyi niin hyvin, että siemenen maahantuonti voitiin kieltää kokonaan 1933. Vuosina 1934-39 ei tuotu lainkaan puna-apilansiementä. Tämä kehitys oli erittäin ilahduttava, koska puna-apila on riittäviin kotoisiin rehuvaroihin pyrittäessä tärkein valkuaislähteemme. 1933 tienoilla puna-apilansiementä oli niin runsaasti, että sen hinta laski vaikuttaen vähentävästi ulkomaisen alsikeapilankin siemenen tuontiin.

Vuoden 1939 jälkeinen sota-aika ei suinkaan ole vähentänyt riippuvaisuuttamme ulkomaisesta siemenestä. Oma siementuotantomme häiriintyi paitsi suorastaan sodan aiheuttamista syistä myös epänormaalisten sääsuhteitten, ennen kaikkea ankarien talvien johdosta. Siemenen puutetta ilmeni jopa viljakasvienkin kohdalla. Siemenentarv€ttamme lisäsivät vielä kasvintuotantomme laajentamisyritykset. Varsinkin juuri- ja vihanneskasveja yritettiin kasvattaa runsaammin, koska ne sellaisenaan ilman välijalostusta kelpaavat ihmisten ravinnoksi.

Ulkomaisen siemenen tarpeemme kasvaessa sen saanti kiristyi samanaikaisesti. Sota oli aiheuttanut suuria häiriöitä monen maan siementuotannossa. Minne taas sodan hävitykset eivät ulottuneet, siellä ankarat talvet tuhosivat talvehtivia siemenviljelyksiä. Useimpien siemenlajien kohdalla esiintyi alituotantoa, mikä siemen- 
Taulukko 1. Siementavaran maahantuonti - Table 1. The import of seeds

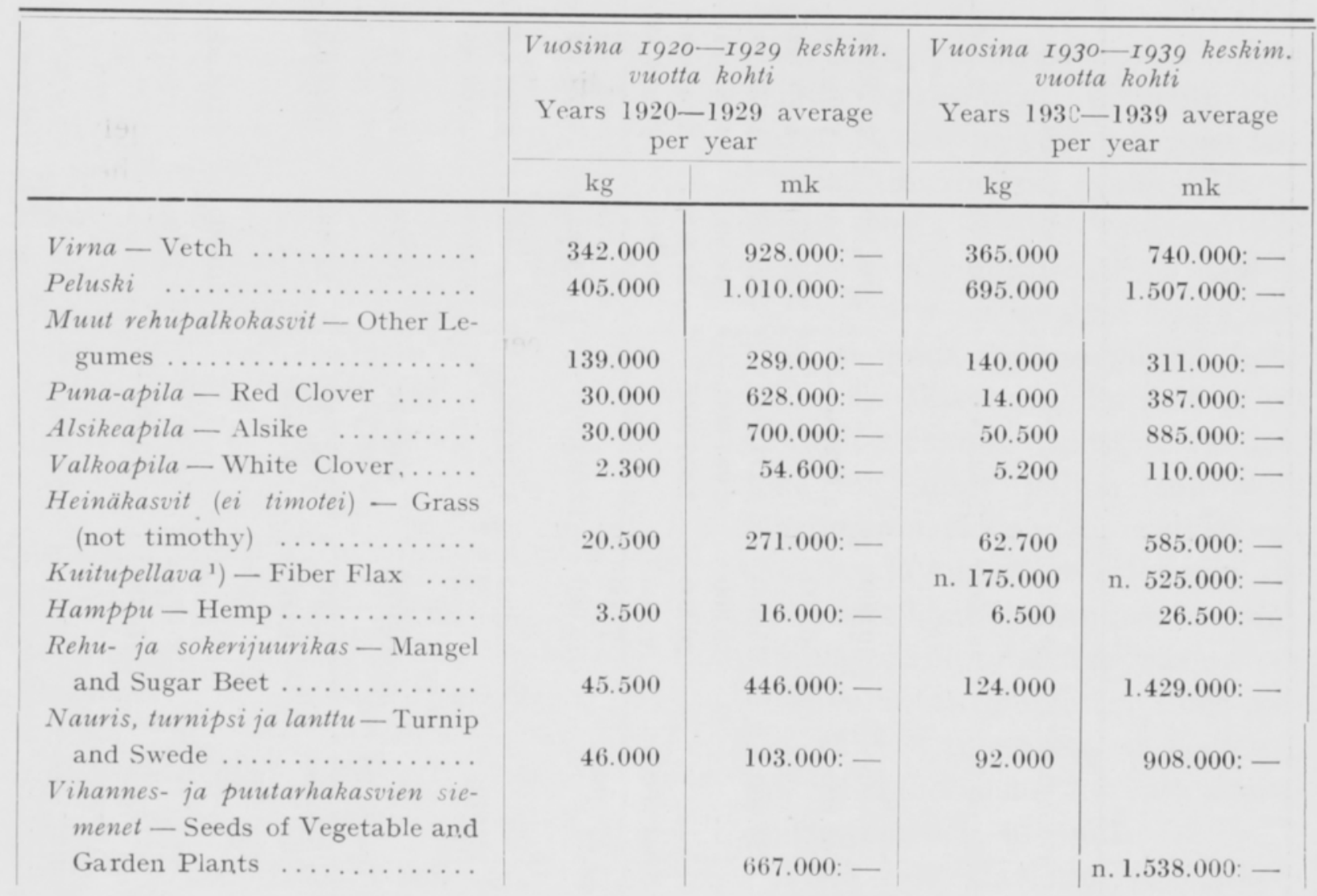

tavaran suuren kysynnän johdosta johti hintojen kohoamiseen. Siementavaran niukkuuden vuoksi hankintojemme hoitaminen tuotti vaikeuksia, joita vielä valuutan säästeliäs käyttö lisäsi. Hankinnat saatiin kuitenkin kutakuinkin hoidetuksi (taulukko $2 ; 10,11,12,13)$. Useimpia siemenlajeja saatiin tuoduksi keskimäärin vuotta kohti samat määrät kuin edellısellä kymmenluvulla.

Toisen maailmansodan loppuvaiheessa siementen kysyntä maailmanmarkkinoilla kasvoi huomattavasti, koska monet sotaan osallistuneet maat pääsivät jo tuossa vaiheessa järjestämään uudelleen lamaantunutta kasvintuotantoaan. Lisääntyneen kysynnän vaikutus näkyy meidänkın kohdallamme vuoden 1945 tuontiluvuissa. Tilanne maailmanmarkkinoilla helpottui kuitenkin verraten nopeasti. Tähän vaikutti suureksi osaksi Yhdysvalloissa sodan aikana kehitetty voimakas siemenviljely, jonka ansiosta tämä maa sodan loputtua pystyi toimittamaan Eurooppaan huomattavia siemenmäärı̈. Yhdysvaltojen siementoimitusten vaikutus oli niin tuntuva, että esim. Tanskalla oli jo vuonna 1947 siementavaroittensa maailmanmarkkinoille sijoittamisvaikeuksia. Tilanteen helpottuminen näkyy myös taulukossa 2 esitetyistä tuontiluvuista. Jo 1946 tuontimme oli huomattavasti runsaampaa kuin v. 1945. Vuoden 1947 kohdalla jatkuu edelleen sama kehityssuunta.

1) Pellavansiemenen tuonti on tullin tuontitilastossa ilmoitettu puristamotavaran yhteydessä, minkä vuoksi siitä ei ole saatavissa aivan tarkkaa tietoa. 


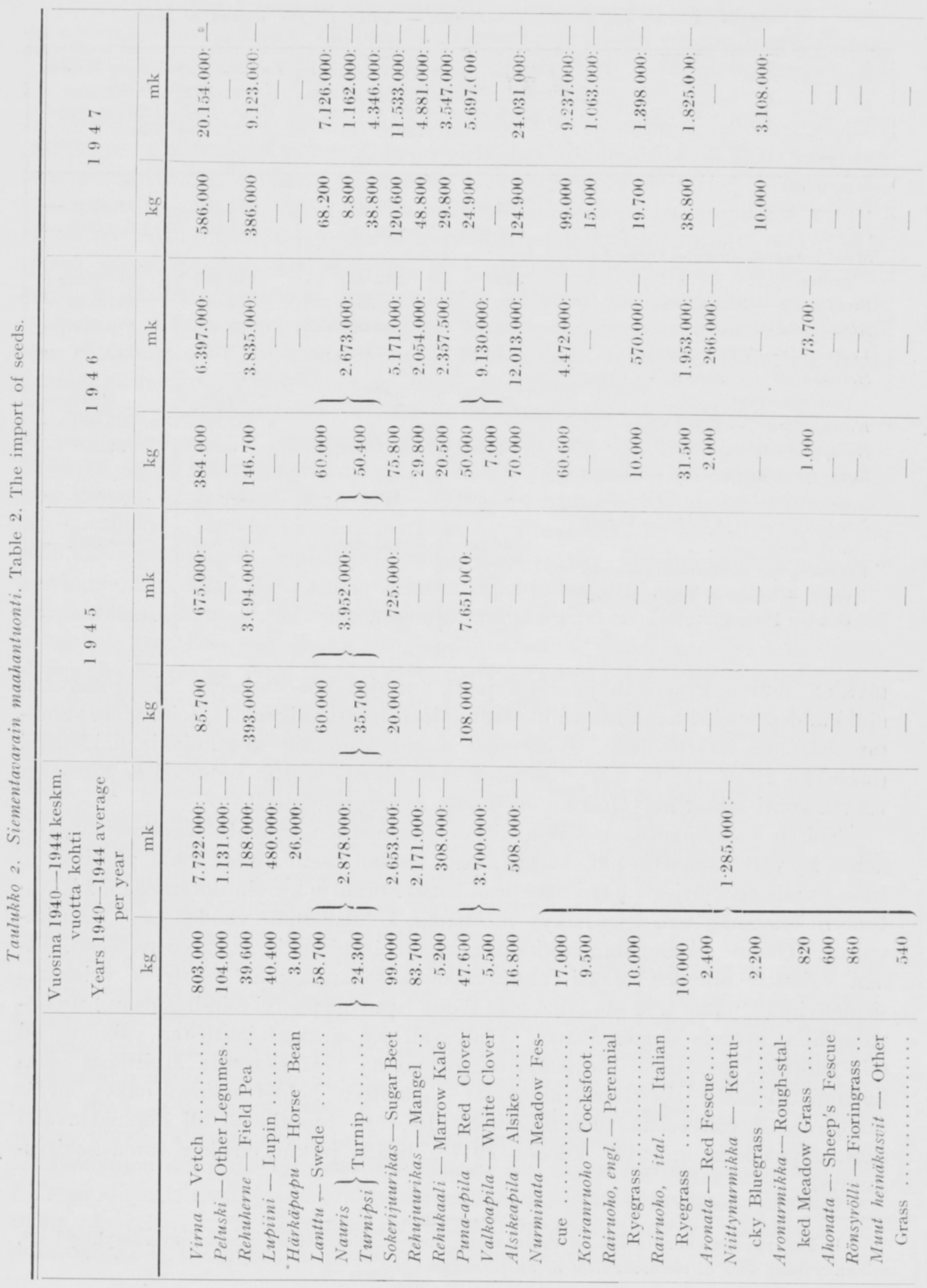




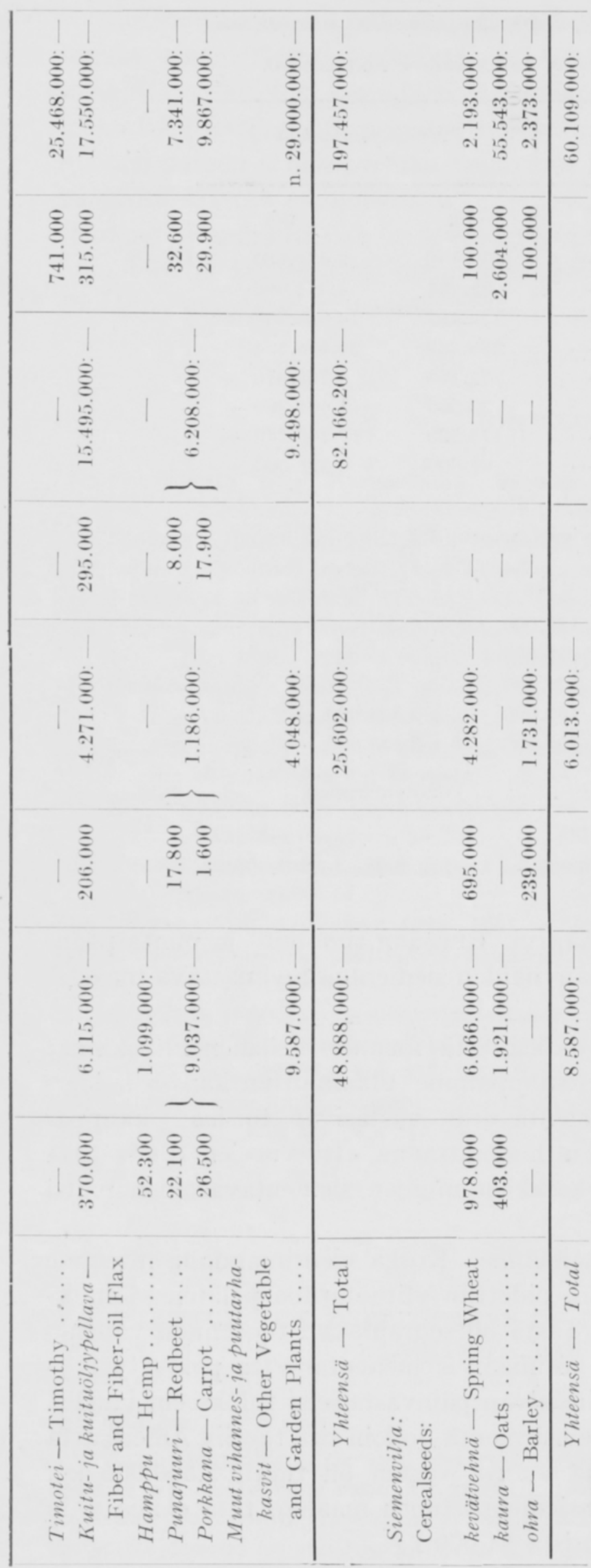

Kotimaan siementuotannon kannalta on erittäin valitettava kehitys, mikä sotavuosista lähtien on tapahtunut puna-apilan siementuotannossa. Se suotuisa suunta, joka siemenen tuotannossa vallitsi 1930luvun alusta lähtien vuoteen 1940 saakka, on muuttunut. Vuodesta 1941 alkaen on maahan tuotu jatkuvasti puna-apılansiementä (taulukko 2). Maahantuodut määrät eivät kuitenkaan vastaa vajaustamme, joka on ollut paljon suurempi. Maailmanmarkkinoilla vallitsevan suuren kysynnän vuoksi emme ole pystyneet hankkimaan maahan suurempia määriä; eräänä syynä on myös ollut valuutan niukkuus. Puna-apilan vähyys tuonnissa on koetettu, mikäli mahdollista, korvata alsikeapilansiemenen tuonnilla.

Vielä valitettavampi kuin äskenkuvattu puna-apilansiemenen tuotannon kehitys on jyrkkä käänne, mikä on aivan viime vuosina tapahtunut timoteinsiemenen suhteen. Viime vuosiin saakka olemme pientä poikkeusta lukuunottamatta olleet omavaraisia timotein siemeneen nähden. Onpa harjoitettu sen vientiäkin jatkuvasti. Edellä viitattiin jo viime vuosisadan puolella tapahtuneeseen siemenviljan ja puntarpäänsiemenen vientiin. Viljakasvien siemenen viennin loputtua puntarpäänsiemenen vienti jatkui. Sen ohella vietiin myös vähäisiä määriä timotein siementä $(4,5,6,7,8,9,10)$.

Vuotuiset vientimäärät ovat ennen toista maailmansotaa yleensä olleet pienet. Eräänä syynä tähän on ollut sekä timotein- että nurmipuntarpäänsiemenen heikko laatu. Toisen maailmansodan vuosina näi- 
Taulukko 3. Timotein- ja nurmipuntarpään siemenen maastavienti

Table 3 . The export of timothy and meadow foxtail seed.

\begin{tabular}{|c|c|c|c|c|}
\hline & \multicolumn{2}{|c|}{$\begin{array}{l}\text { Timotei } \\
\text { Timothy }\end{array}$} & \multicolumn{2}{|c|}{$\begin{array}{l}\text { Nurmipuntarpää } \\
\text { Meadov foxtail }\end{array}$} \\
\hline & $\mathrm{kg}$ & $\mathrm{mk}$ & $\mathrm{kg}$ & $\mathrm{mk}$ \\
\hline 1940 & 1.257 .482 & 19.268.964:- & 76.186 & $3.430 .025:-$ \\
\hline 1941 & 684.015 & $16.897 .678:-$ & 92.234 & 4.718.666: 一 \\
\hline 1942 & 307.840 & $12.926 .760:-$ & 174.482 & $14.955 .566:-$ \\
\hline 1943 & 1.189 .724 & $50.332 .403:-$ & 398.269 & $35.508 .554:-$ \\
\hline 1944 & 1.946 .434 & $84.205 .787:-$ & 77.155 & $6.755 .870:-$ \\
\hline 1945 & - & - & 23.300 & $1669.300:-$ \\
\hline 1946 & 99.980 & $10.723 .439:-$ & 175.520 & $17.460 .249:-$ \\
\hline 1947 & 500 & $62.000:-$ & 61.600 & $6.322 .000:-$ \\
\hline
\end{tabular}

Heinänsiemenen vienti vuotta kohti

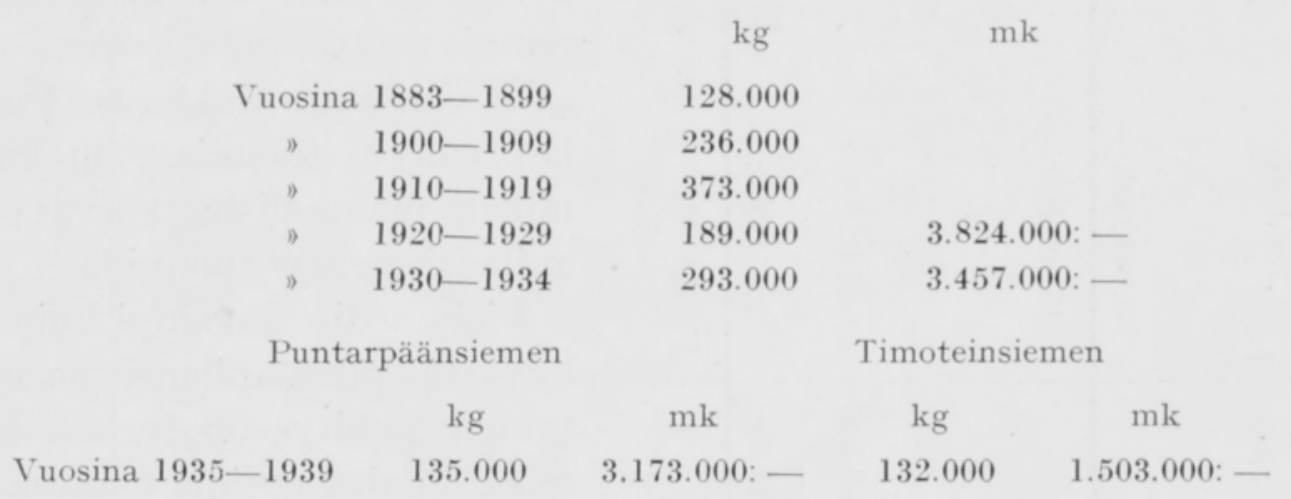

den molempien siemenlajien kysyntä lisääntyi. Runsaan timotein- ja puntarpäänsiemenen tuotannon turvin saatiin aikaan näiden siementen huomattava maastavienti (taulukko $3 ; 10,11,12,13$ ).

Tämän viennin ansiota oli suureksi osaksi, että maamme siemenenhankinnat saatiin hoidetuksi niinkin hyvin. Siemenkauppamme ulkomaitten kanssa hoidettiin tällöin kompensatiokauppana: siementavarat vastasivat toisiaan kauppasopimuksia tehtäessä. Tämä vienti oli niin huomattavaa, että vuosien 1940-1944 viennistä saaduilla tuloilla rahoitettiin kaikkien muiden siementavaroidén paitsi siemenviljan samanaikainen tuonti.

Sodan päätyttyä tapahtui kuitenkin käänne. Koska vientimahdollisuutemme olivat vähentyneet melkein olemattomiin, pidettiin ylituotantoa peläten säännöstelty timoteinsiemenen hinta alhaisena. Tästä oli seurauksena tuotannon väheneminen niin suuressa määrin, ettei edes kotimaan siemenentarvetta pystytty tyydyttämään. Kahdessa vuodessa päädyttiin aivan päinvastaiseen tulokseen: vuoden 1947 kylvöjä varten oli hankittava timoteinsiementä, jolloin sitä tuotiin Amerikasta $741.000 \mathrm{~kg}$. Mainittakoon, että kuluvaa vuotta varten on tuotu $2.350 .000 \mathrm{~kg}$. Koko itsenäisyysaikanamme on timoteinsiementä tuotu maahan tätä ennen vain kerran: v. 1927, jolloin sitä tuotiin Ruotsista $94.000 \mathrm{~kg}$. 
Tällä kymmenluvulla tapahtunut kehityssuunta, lisääntynyt riippuvaisuutemme ulkomaisesta siemenestä, on erittäin haitallinen maamme kasvintuotannon kannalta. Siemenen saannin vaikeutuessa on aina uhkaamassa epävarmuus, saammeko kylvösiemenentarpeemme tyydytetyksi. Sitä paitsi useissa tapauksissa ulkomainen siemen ei alkuperänsä vuoksi ole kotimaisen veroista. Oman maan siementuotanto säästää melkoisesti myös ulkomaista valuuttaa. Vastaista kasvintuotantoamme suunniteltaessa on myös kylvösiemenkysymykseen kiinnitettävä vakavaa huomiota ja kehitettävä siemenviljelymme niin paljon kuin mahdollista kasvintuotantomme tarpeita vastaavaksi.

\section{KIRJALLISUUTTA.}

(1) Grotenfelt, G. ja Axelsson, V. Suomen Kylvösiemenyhdistyksen tarkoitus, suunnittelu ja tulevaisuus. S. Kylvösiemenyhd. kirjasia, 1. Helsinki 1906.

(2) Suomen Kylvösiemenyhdistyksen vuosikirja 1. Helsinki 1915.

(3) Suomen Kylvösiemenyhdistyksen vuosikirja 2. Helsinki 1917.

(4) Kauppa ja merenkulku. Vuodet 1883-1890. S. Virall. Tilasto. Helsinki.

(5) Suomen kauppa ja laivaliike Venäjän ja ulkovaltojen kanssa sekä tullilaitoksen ylöskanto. Vuodet 1891-1902. S. Virall. Tilasto. Helsinki.

(6) Suomen kauppa Venäjän ja ulkovaltojen kanssa sekä tullilaitoksen ylöskanto. Vuosi 1903. S. Virall. Tilasto. Helsinki.

(7) Suomen kauppa Venäjän ja ulkovaltojen kanssa sekä tullilaitoksen ylöskanto. Vuodet 1904 -1916. S. Virall. Tilasto. Helsinki.

(8) Suomen kauppa ulkovaltojen kanssa sekä tullilaitoksen ylöskanto. Vuodet 1917-1918. S. Virall. Tilasto. Helsinki.

(9) Suomen kauppa ulkomaiden kanssa sekä tullilaitoksen kanto. Vuodet 1919_1924. S. Virall. Tilasto. Helsinki.

(10) Ulkomaankauppa. Vuodet 1925-1946. S. Virall. Tilasto. Helsinki.

(11) Siemenkauppiaitten yhdistyksen asiakirjat. Vuodet 1942-1947. Siemenkauppiaitten yhdistyksen arkisto.

(12) Kertomukset Valtion Siementarkastuslaitoksen toiminnasta 1-19. toimintavuosina. Maataloushallituksen tiedonantoja, 100, 146, 150,162, 164, 173, 180, 186, 198, 203, 211, 219, 223, $229,234,243,250,258,265$. Helsinki.

(13) Valtion Siementarkastuslaitos. Toimintavuodet $20-27$. Maataloushallituksen tiedonantoja, $2 \gamma 1,273,27 \gamma, 282,287,291,293,295$. Helsinki.

\section{S U M M A R Y.}

A REVIEW OF THE DEVELOPMENT OF THE SEED PRODUCE OF FINLAND IN THE LIGHT OF IMPORT AND EXPORT.

Lissa Mali.

In the beginning of the 19th century Finland may have been able to meet its own demand for seeds as rye, barley, oats, meadow foxtail etc. were exported even at that time. The production of seeds was not, however, capable of following the rapid development of plant production for which reason the demand for imported seeds increased during the latter part of the 19th century and in the 
beginning of the 20th century. Attempts were made to augment the production of seeds in the 1910's and about 1920. At this time a great interest in seed cultivation was observable. After the first World War it was, however, checked by the supply of cheaper foreign seeds. In the 1920's and the 1930's the amount of imports grew on the part of the majority of seed kinds (Table 1). During the present decade our dependence on foreign seeds has constantly increased (Table 2).

From the plant production standpoint the development in this direction is exceedingly deplorable as the imported seeds, owing to their origin, seldom meet the requirements set upon the domestic ones. Finland is able to produce most of the different kinds of seeds and also to export them which fact has been proved by the considerable export of meadow foxtail and timothy seed in the 1940's (Table 3). For this reason serious attention must be paid to the seed problem when planning the future plant production, and the cultivation of seeds must be developed as far as possible to meet the demand of our own plant production. 